\title{
Manuel Álvarez-Valdes y Valdés: Noticia de Jovellanos y su entorno. Gijón, Fundación Alvargonzález, 2006.
}

Secularmente, las investigaciones jovellanistas han venido discurriendo en dos escenarios diferenciados y no siempre complementarios. Desde el mundo académico, los análisis se han centrado generalmente en la valoración de la obra interdisciplinar del ilustrado gijonés: escritos económicos, políticos, asturianistas... Otra tradición jovellanista, extramuros del mundo universitario, ha forjado sus monografías en otras direcciones: catalogación de fondos, biografía, diarios, correspondencia... Obviamente, en ningún caso los escenarios en cuestión prejuzgan la calidad de los actores, y, por lo mismo, en ambas «escuelas» es posible encontrar buenos y malos estudiosos; como también resulta obvio recordar que fuera del ámbito universitario ejercen jovellanistas de reconocido prestigio científico. Por último, conviene señalar que hay estudiosos que participan de ambas trayectorias.

Es el caso de Manuel Álvarez-Valdés y Valdés, doctor en derecho, abogado del Estado y académico correspondiente de las Reales Academias de la Historia y de Jurisprudencia y Legislación. Su sólida formación universitaria y su dilatada experiencia en el mundo empresarial le han permitido conciliar el rigor metodológico con la libertad para seleccionar los temas de su agenda investigadora. $\mathrm{Y}$ así, en 2002, daba a la luz su Jovellanos: enigmas y certezas. Más allá de las biografías al uso, el autor se adentraba, protegido con sólido pertrecho documental, en los aspectos más polémicos, y a menudo orillados, de la biografía del ilustrado gijonés: amores, envenenamiento, prisión, compromiso político, o relaciones con Godoy, entre otros. Al final de su obra, la figura de Jovellanos resulta fortalecida porque nos acerca perfiles que hasta entonces permanecían en la penumbra. Por añadidura, esos nuevos matices permiten una mejor contextualización de su obra escrita y de su trayectoria biográfica. El trabajo de archivo y bibliográfico asientan una obra que, como las de Caso o Varela, ya se ha convertido en una pieza clásica e imprescindible.

El volumen que nos ocupa, Noticia de Jovellanos y su entorno, completa y redondea el trabajo anterior, del que pudiera considerarse una segunda parte. En este caso, el objetivo de la investigación se amplía desde el horizonte biográfico o personal al circunstancial e histórico: la Sevilla de Olavide, las relaciones con los Holland, con el marqués Caballero, con la marquesa de Santa Cruz de Rivadulla o con Ceán Bermúdez son algunos de los contornos recreados y analizados. Su reconstrucción añade variables nuevas al instrumental analítico de los jovellanis- 
tas, a la vez que ofrece una arquitectura argumental que reforzará la coherencia de las tesis en torno al pensamiento y actitudes del polígrafo asturiano.

Paso a paso, y sin las servidumbres de tiempo y espacio que suelen presidir los trabajos académicos, Manuel Álvarez-Valdés recorre con detalle archivos públicos y privados, correspondencia, bibliotecas y todo tipo de fuentes que le permitan trasladar hacia una nueva frontera el terreno ganado al conocimiento. El Archivo Histórico Nacional y el del Congreso, el de la Real Academia de la Historia y el del Palacio Real, los del marqués de Santa Cruz de Rivadulla, el de la Real Sociedad Patriótica de Amigos del País de Sevilla o el de la Fundación Alvargonzález, entre otros muchos, son testigos de una investigación rigurosa en la que, como diría uno de los fundadores de la historiografía moderna, A. de Capmany y Montpalau, «nada se afirma que no pueda ser probado». Por lo mismo, el investigador, sin traspasar los límites de la documentación y abandonando toda suerte de tópicos, respeta los «enigmas» con que Jovellanos supo trazar la frontera entre su vida pública y privada.

En el epílogo a su trabajo, reproduce Manuel Álvarez-Valdés las atinadas y sentidas palabras con que lord Holland evocaba a su amigo: «sus cualidades morales igualaban a su inteligencia; la delicadeza de su gusto era semejante a la de su espíritu, la pureza de su lenguaje era la imagen de su vida ordenada...».

Con ellas, despedimos esta breve reseña y dejamos al lector que se sumerja en la placentera y provechosa lectura de una obra de referencia imprescindible. 